\title{
Biodegradation of fluoroquinolone antibiotics and the climbazole fungicide by Trichoderma species
}

\author{
Q1 7 Rayana Manasfi ${ }^{1,2} \cdot$ Serge Chiron $^{1} \cdot$ Nicola Montemurro $^{2} \cdot$ Sandra Perez $^{2} \cdot$ Monica Brienza $^{1}$ \\ Received: 23 August 2019 / Accepted: 13 March 2020 \\ 10 (C) Springer-Verlag GmbH Germany, part of Springer Nature 2020
}

\section{Introduction}

Soil and water pollution by contaminants of emerging concern (CECs) in the meantime is a worldwide problem. Among all CECs, pharmaceuticals and personal care products (PPCPs) are a large family of chemicals that can be bio-accumulated, persistent and toxic and may have a

Responsible editor: Gerald Thouand

Electronic supplementary material The online version of this article (https://doi.org/10.1007/s11356-020-08442-8) contains supplementary material, which is available to authorized users.

Monica Brienza

monica.brienza@umontpellier.fr

1 UMR HydroSciences 5569, Montpellier University, IRD, 15 Avenue Ch. Flahault, 34093 Montpellier Cedex 5, France

2 Water and Soil Quality Research Group, IDAEA-CSIC, c/Jordi Girona 18-26, 08034 Barcelona, Spain negative effect on the environment and/or human health, even at trace level. Their main direct entrance to the environment is through municipal or industrial wastewater effluents (Chen et al. 2004; Couto et al. 2019; Kümmerer 2011) because they are not completely removed by biological wastewater treatment plants. The inefficiency of current activated sludge processes for PPCPs removal calls for innovative processes (Couto et al. 2019; Petrie et al. 2015; Phonsiri et al. 2019). Advanced oxidation processes have demonstrated high potential to remove PPCPs but the high energy consumption and the formation of toxic byproducts can limit their implementation (Brienza et al. 2019; Fatta-Kassinos et al. 2011; Huang et al. 2018). In this context, bioremediation techniques using fungal strains for the removal of PPCPs have several advantages. They can be eco-friendly, feasible and cost-effective alternative treatments in comparison with other remediation techniques (Kumar et al. 2019; Olicón-Hernández et al. 2017). Many studies (Čvančarová et al. 2015; Jelic et al. 2012; Prieto et al. 2011) have been focused on the white rot 
fungi (WRF) such as Trametes versicolor. Good removal efficiencies accomplished by these WRF have been attributed to the action of a nonspecific enzymatic system that includes extracellular ligninolytic enzymes such as laccase, lignin peroxidase, manganese peroxidase and versatile peroxidase. The extracellular enzymatic system has not been found the only responsible for PPCPs degradation. In fact, the intracellular enzyme system also plays an important role thanks to the action of cytochrome P450 enzymes (CYP450) (Asgher et al. 2008; Čvančarová et al. 2015; Durán and Esposito 2000; Prieto et al. 2011; Tanaka et al. 1999). Extracellular ligninolytic enzymes are only produced by some organisms in contrast to CYP450 that are ubiquitous in all biological kingdoms. However, one limitation of the use of WRF in PPCPs remediation has been the difficulty for the inoculated fungus to successfully compete with the other microorganisms growing in bioreactors (Badia-Fabregat et al. 2017).

In contrast to WRF, the use of filamentous fungi from the genus Trichoderma has been poorly investigated for PPCP elimination from domestic wastewaters (Buchicchio et al. 2016) in spite of several appealing features: (1) Their prevalence in the environment is primarily due to their ability to rapidly grow and propagate in adverse environmental conditions, their ability to use different sources of carbon and nitrogen as well as their ability to effectively compete with bacteria through the synthesis of antibiotics. (2) They are able to accumulate heavy metals (Hoseinzadeh et al. 2017) and nutrients (Hultberg and Bodin 2017) and to grow in wastewater effluents to produce cellulase (Libardi et al. 2017). (3) There is a possibility for treated wastewater reuse in irrigation without any additional treatment as Trichoderma spp. are beneficial for plant growth.

The overall purpose of this study was to investigate the removal kinetics and mechanisms of targeted PPCP degradation by ubiquitous soil Trichoderma spp. (i.e., Trichoderma asperellum and Trichoderma harzianum) and to identify their biotransformation products (TPs) in liquid phase and under aerobic condition. Fluoroquinolone antibiotics (i.e., ciprofloxacin (CIP) and ofloxacin (OFL)) are widely used in both human and veterinary medicines as antimicrobial agents, hence their high detection (ng/L up to $\mu \mathrm{g} / \mathrm{L}$ ) in treated wastewater effluent (Kim and Aga 2007; Rabiet et al. 2006; Togola and Budzinski 2008). They were selected as probe compounds because their biotransformation have been widely investigated by WRF and others fungi species offering a starting point for comparison (Gros et al. 2014; Prieto et al. 2011; Wetzstein et al. 1999). Climbazole (CLB) is an antimycotic imidazole drug used as an active ingredient in antidandruff shampoo. It was selected on its ubiquitous occurrence in wastewater effluents (Richter et al. 2013), on its low biodegradability in activated sludge processes and due to its antimycotic properties.

\section{Material and methods}

Analytical standards of CIP, OFL, CLB, desethylene ciprofloxacin (hydrochloride), ciprofloxacin formamide and 4chlorophenol were of high purity grade $(>98 \%)$ and obtained from Sigma-Aldrich (St Quentin-Fallavier, France). Climbazole alcohol (CLB-OH) was synthetized as previously reported (Brienza and Chiron 2017). Ultra-pure water (UPW) was obtained using a Millipore system. LC-MS grade acetonitrile and HPLC water were purchased from Merck (Darmstadt, Germany). Formic acid ( $\geq 96 \%$, ACS reagent), ammonium fluoride, ammonium acetate, HPLC grade methanol $(\mathrm{MeOH}), 0.45 \mu \mathrm{m}$ and $0.22 \mu \mathrm{m}$ PTFE syringe filters, potato dextrose agar and malt extracts broth were supplied by Sigma-Aldrich. Oasis HLB (30 mg sorbent/ $1 \mathrm{~cm}^{3}$ and $200 \mathrm{mg}$ sorbent $/ 6 \mathrm{~cm}^{3}$ ) solid phase extraction (SPE) cartridges were from Waters Corporation (Milford, MA).

Stock solutions of CIP and OFL were prepared in water/ $\mathrm{MeOH}(50 / 50, \mathrm{v} / \mathrm{v})$ with $2 \%$ of hydrochloric acid $(>90 \%)$ at a concentration of $400 \mathrm{mg} / \mathrm{L}$, while CLB was prepared in $\mathrm{MeOH}$ at a concentration of $1000 \mathrm{mg} / \mathrm{L}$. Serial dilutions were performed with UPW and stored at $5^{\circ} \mathrm{C}$, while stock solutions were stored at $-20^{\circ} \mathrm{C}$. Standards were sterilized using PTFE $0.22-\mu \mathrm{m}$ syringe filter before their usage in the experiments.

Trichoderma harzianum (TH, CBS 226.95) and Trichoderma asperellum (TA, CBS 433.97) were obtained from Westerdijk Fungal Biodiversity Institute (Utrecht, Netherlands) as pure strains. The two strains were cultivated separately in sterile petri dishes ( $9 \mathrm{~cm}$ of diameter) filled with potato dextrose agar at $25^{\circ} \mathrm{C}$. Fungi replications were routinely made every week by transferring one plug to a new potato dextrose agar petri dish. Potato dextrose agar was prepared by dissolving $39 \mathrm{~g}$ in $1 \mathrm{~L}$ of UPW and boiled until complete dissolution. Prepared solutions were sterilized in an autoclave for $15 \mathrm{~min}$ at $121^{\circ} \mathrm{C}$. Finally, $1 \mathrm{~mL}$ of $10 \%$ lactic acid sterilized using $0.22-\mu \mathrm{m}$ PTFE syringe filter was added to suppress bacterial growth. In vivo degradation experiments were carried out using the mycelial formed from both Trichoderma strains.

\section{Biodegradation experiments}

Degradation experiments were carried out in sterile specimen cups, each containing $60 \mathrm{~mL}$ of low nutrient liquid medium made up by $0.25 \mathrm{~g} / \mathrm{L}$ of peptic digest of animal tissue and $0.15 \mathrm{~g} / \mathrm{L}$ of beef extract ( $\mathrm{pH} 4.9$ ), which was sterilized in an autoclave for $15 \mathrm{~min}$ at $121^{\circ} \mathrm{C}$. Each cup was inoculated with three mycelial plugs of $0.8 \mathrm{~cm}^{2}$. The medium was spiked from a stock solution containing the selected compounds achieving a $200 \mu \mathrm{g} / \mathrm{L}$ initial concentration for each one. The spiking concentration was low enough to avoid any possible toxic
109

110

111

112

113

114

115

116

117

118

119

120

121

122

123

124

125

126

127 
effect on fungi. Each compound was spiked separately with each of the two Trichoderma strains. The degradation of selected compounds was assessed by comparing their concentrations with the abiotic control cups during time experiments. Thereafter, cups were incubated at $25^{\circ} \mathrm{C}$ in an orbital shaker at $135 \mathrm{rpm}$ for 13 days. Experiments were carried out in the dark to avoid any compound photolysis. Samples $(1 \mathrm{~mL})$ from each cup were taken at specific time points $(0,2,5,7,13$ days), filtered at $0.45 \mu \mathrm{m}$ and purified by SPE as described in the following section.

Besides the experimental treatment, abiotic controls (where the matrix contained target compounds exposed to the same experimental conditions but without fungi) were used to assess potential abiotic degradation. An additional experiment was carried out, where $5 \mathrm{mM}$ of 1 -aminobenzotriazole (ABT) was added as a CYP450 inhibitor in order to understand the role of intracellular enzymes in degradation processes.

To evaluate the role of the sorption processes in the CECs removal, two methods (i.e., ultrasonication and heat-killed fungi) were applied as reported by Buchicchio and coauthors (Buchicchio et al. 2016). Briefly, the remaining liquid medium at $t=13$ days was passed through Oasis HLB cartridges $\left(200 \mathrm{mg}\right.$ sorbent $\left./ 6 \mathrm{~cm}^{3}\right)$. For the ultrasonication method, the SPE sorbent was removed and sonicated in $\mathrm{MeOH}$ for $5 \mathrm{~min}$. Extracts were subsequently centrifuged and the liquid phase recovered. When the heat-killed fungi approach was employed, the retained analytes were eluted with $2 \times 5 \mathrm{~mL}$ $\mathrm{MeOH}$, while fungal cells remained absorbed in the cartridges. Subsequently, SPE cartridges were autoclaved for $30 \mathrm{~min}$ at $121^{\circ} \mathrm{C}$. The sorbent phase was then washed with $2 \times 5 \mathrm{~mL} \mathrm{MeOH}$. In both methods, eluates were concentrated until full dryness under a gentle nitrogen flow. Residues were collected with $1 \mathrm{~mL}$ of LC-MS mobile phase (ACN/water, $5 / 95 \%, v / v)$, filtered with $0.22-\mu \mathrm{m}$ PTFE syringe filters and finally transferred to vials ready for injection.

\section{Analytical methods}

For the biodegradation analysis, an extraction and purification SPE method was implemented using Oasis HLB cartridges (30 mg sorbent $/ 1 \mathrm{~cm}^{3}$ ). The conditioning step was performed with $1 \mathrm{~mL} \mathrm{MeOH}$ followed by $1 \mathrm{~mL}$ UPW. A total of $1 \mathrm{~mL}$ of filtered sample was passed through the cartridge followed by $1 \mathrm{~mL}$ of UPW for washing. Cartridges were dried under vacuum until total dryness and finally eluted with $2 \times 1 \mathrm{~mL}$ of $\mathrm{MeOH}$. Eluates were totally dried under a gentle nitrogen flow at $55^{\circ} \mathrm{C}$, reconstituted with $1 \mathrm{~mL}$ of LC-MS mobile phase (ACN/water, $5 / 95 \%, v / v$ ) and filtered with $0.22-\mu \mathrm{m}$ PTFE syringe filters before injection. The employed SPE extraction provided high recoveries for all studied parent compounds (>90\%).

Kinetics studies and TPs identification were performed using a SCIEX ExionLC ${ }^{\text {TM }}$ AD Quadrupole-Time of Flight mass spectrometer (Q-TOF, Redwood City, CA, USA). For TPs, identification samples were injected at 7 days of incubation time, where the highest TP concentrations were often reached. A total of $5 \mu \mathrm{L}$ of purified samples were injected with an auto-sampler temperature maintained at $8^{\circ} \mathrm{C}$. Separation was performed using a Hibar® HR Purospher® STAR RP-C 18 column $(100 \times$ $2.1 \mathrm{~mm}$ i.d., $2 \mu \mathrm{m}$ particle size, Merck, Darmstadt, Germany), maintained at $40^{\circ} \mathrm{C}$ in the column oven. A fast elution of $10 \mathrm{~min}$ was carried out using a binary linear gradient composed of $2 \mathrm{mM}$ ammonium fluoride in water (A) and ACN (B) for negative electrospray ionization, and $5 \mathrm{mM}$ ammonium acetate and $0.1 \%$ of formic acid in water (A) and $\mathrm{ACN}(\mathrm{B})$ for positive ionization mode, at a flow rate of $0.5 \mathrm{~mL} / \mathrm{min}$.

High resolution mass spectrometry data were acquired using the SWATH acquisition mode workflow consisting of a single TOF-MS experiment over a $\mathrm{m} / \mathrm{z}$ range from 70 to $950 \mathrm{Da}$ with an accumulation time (AT) of $130 \mathrm{~ms}$, followed by $3 \mathrm{MS} / \mathrm{MS}$ experiments with variable Q1 windows (30 to $900 \mathrm{~m} / \mathrm{z}, 50 \mathrm{~ms}$ AT) using a Collision Energy (CE) of 10, 20, 30 and $35 \mathrm{eV}$ and a collision energy spread of $\pm 15 \mathrm{eV}$ for the latest. The source conditions for the system were optimized as follows: Ion spray voltage was set to $5500 \mathrm{~V}$; source temperature and nitrogen gas flows (atomizing gas, GS1 and auxiliary gas, GS2) were set to $550{ }^{\circ} \mathrm{C}$ and $60 \mathrm{psi}$, respectively. Curtain gas was set to $35 \mathrm{psi}$ and Declustering Potential (DP) to $80 \mathrm{~V}$. Any drift in the mass accuracy was automatically corrected and maintained throughout batch acquisition by infusion of reserpine reference standard $\left(\mathrm{C}_{33} \mathrm{H}_{40} \mathrm{~N}_{2} \mathrm{O}_{9}, \mathrm{~m} / \mathrm{z}\right.$ 609.28066) for positive ionization and a cluster of trifluoroacetic acid (5(TFA-Na) $+\mathrm{TFA}^{-}, \mathrm{m} / \mathrm{z}$ 792.85963) for negative ionization. Calibration was running every 5 samples during the batch acquisition using the Calibrant Delivery System (CDS). All data were acquired and processed using SCIEX OS software version 1.5. A suspect screening workflow was used. A csv-database was made up of a list of possible TPs with their molecular formula, exact mass and structure. This list was generated from a literature search of TPs of OFL, CIP and CLB generated during photochemical experiments, other oxidative treatments and biodegradation/ metabolism experiments and prioritizing some metabolic products estimated using the BiotransformationMassDefects software tool provided from Agilent (Agilent Technologies, Barcelona, Spain). High confidence identification of new TPs was based on accurate masses of pseudo-molecular ions and unique fragment ions interpretation.

\section{Results and discussion}

\section{Biotransformation of CIP, OFL and CLB} by Trichoderma species

Abiotic controls showed high compound stability during the incubation time (data not shown). Due to these results, the 
concentration variations have been assigned to sorption on fungi and to biodegradation processes. Sorption processes including absorption (contaminants inside the biomass) and adsorption to the biomass surface were indirectly evaluated by setting up a control flask with thermal inactivated fungus or directly evaluated by compounds ultrasonic extraction. The sorption kinetics was not considered. Results showed that biosorption played a very limited role in the observed contaminant removal $(<10 \%)$ (data not shown). This lack of CECs biosorption is consistent with the results of previous experiments in which no sorption processes of carbamazepine, clarithromycin and tebuconazole on Trichoderma biomass occurred (Buchicchio et al. 2016; Obanda et al. 2008).

Concentrations of contaminants were measured at the beginning and at the end of the experiments, and the difference in concentrations is mainly attributed to biodegradation processes. The results are shown in Fig. 1 as eliminated percentage of each compound by both Trichoderma sp. (T. harzianum and T. asperellum), in presence and in absence of CYP450 inhibitor 1-aminobenzotriazole (ABT). Further explanations on the eliminated fraction by Trichoderma spp. are discussed in the rest of this section.

All targeted compounds were biotransformed by whole cells of Trichoderma spp. Biodegradation kinetics of parent compounds and transformation products (TPs) generation kinetics for CLB and CIP are shown in Figs. 2 and 3, respectively, in presence and in absence of ABT. The different experiments are all spiked at $200 \mu \mathrm{g} / \mathrm{L}$ as initial concentration. Recovery values for CLB, CIP and OFLO were determined to be $92 \pm 8 \%, 94 \pm 13 \%$ and $90 \pm 20 \%$, respectively. Complex extracts were obtained for these biological samples, and high matrix effects were observed accounting for the high coefficients of variation. OFL could not be properly quantified due to strong matrix effects in LC/MS neither its TPs due to the lack of analytical standards. OFL kinetic profiles are therefore reported in Supporting Material (SM, Fig. 1SM) on the basis of determination of peak area. Strong differences were observed between both fungi strains. At the end of incubation time (13 days), T. harzianum achieved almost complete CLB removal (91\%) (Fig. 2c) instead of only 32\% (Fig. 3c) and $21 \%$ (Fig. 1SM) for OFL and CIP, respectively.

In contrast, $T$. asperellum was the most efficient strain towards the two fluoroquinolone antibiotics, with the highest biodegrability observed for CIP. After 13 days of incubation, $82 \%$ (Fig. 3a) and $44 \%$ (Fig. 1SM) of CIP and OFL were eliminated respectively, while only a slight biodegradation rate was observed for CLB (14\%) (Fig. 2a). Biphasic kinetics including firstly a fast degradation phase and secondly a slower degradation phase might be related to nutrient privation after 2-3 days of incubation because biodegradation experiments were carried out in low nutrient liquid medium to prompt enzymes induction. The difference of the degradation rates observed between CIP and OFL may be justified by the difference in their molecular structures. However, this was not conclusive since both fluoroquinolones showed similar elimination rates when cultivated with the WRF T. versicolor and P. ostreatus (Čvančarová et al. 2015; Prieto et al. 2011). Higher elimination rates were observed for CIP when cultivated with P. tigrinus, while OFL underwent higher elimination rates when cultivated with $D$. squalens after 14 days of incubation (Čvančarová et al. 2015).

The contribution of internal CYP450 enzymes was evaluated by adding $5 \mathrm{mM}$ of 1 -aminobenzotriazole (ABT) in whole cultures. After $1 \mathrm{~h}$, targeted compounds were added to fungal cultures. Degradation rates were $30 \%$ (Fig. 1SM) and $37 \%$ (Fig. 2d) less for OFL and CLB, respectively for T. harzanium, while no inhibition was observed for T. asperellum (deficit around 7\%, (Fig. 1SM and Fig. 2b). On the contrary, CIP degradation was slightly affected when CYP450 inhibitor was added to T. harzanium (8\% less, Fig. 3d), while it was $25 \%$ (Fig. 2b) less when added to $T$. asperellum. This result is in contrast with WRF for which the ABT addition led to significant inhibition of pharmaceuticals biodegradation (Prieto et al. 2011). However, it was
Fig. 1 Percentage degradation (\%) of CLB, OFL and CIP by T. asperellum and T. harzanium in presence and in absence of 1amonibenzotriazole (ABT) after 13 days of incubation

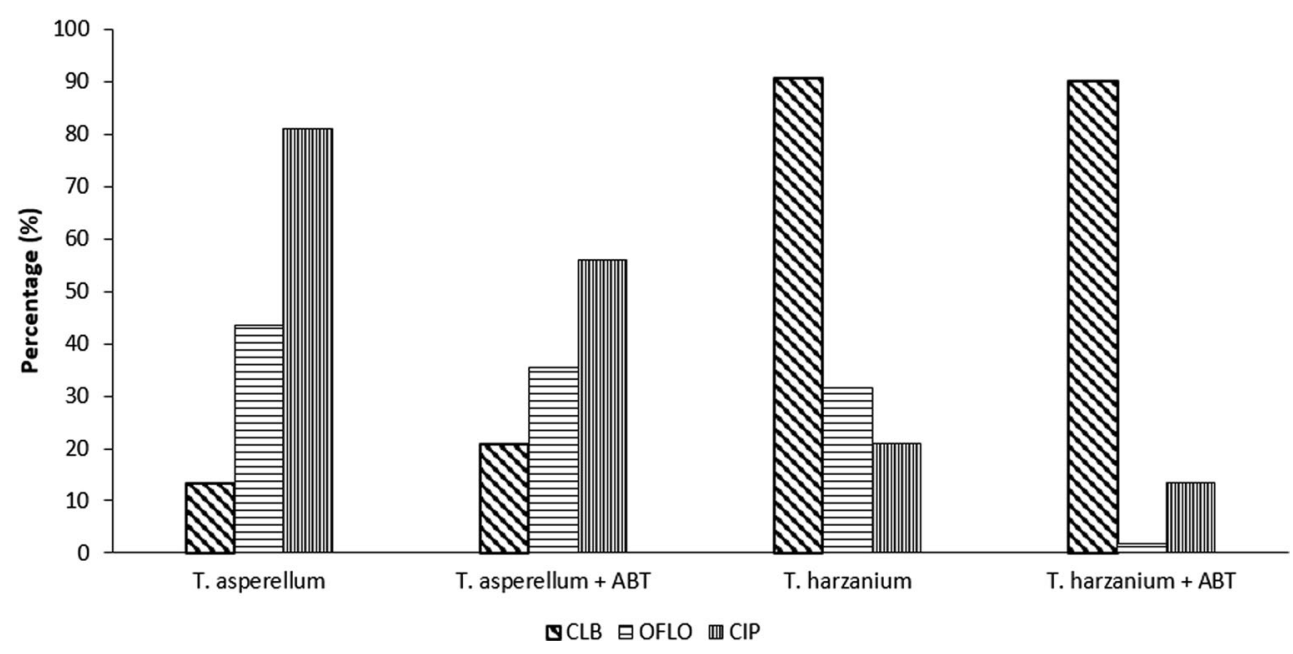


a

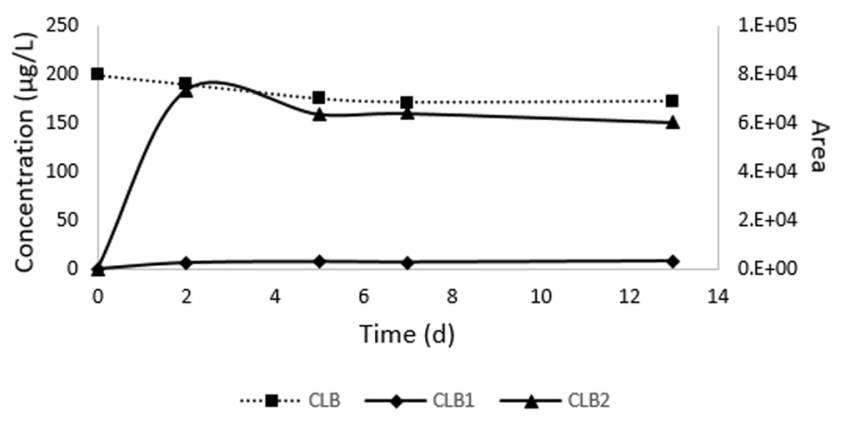

b

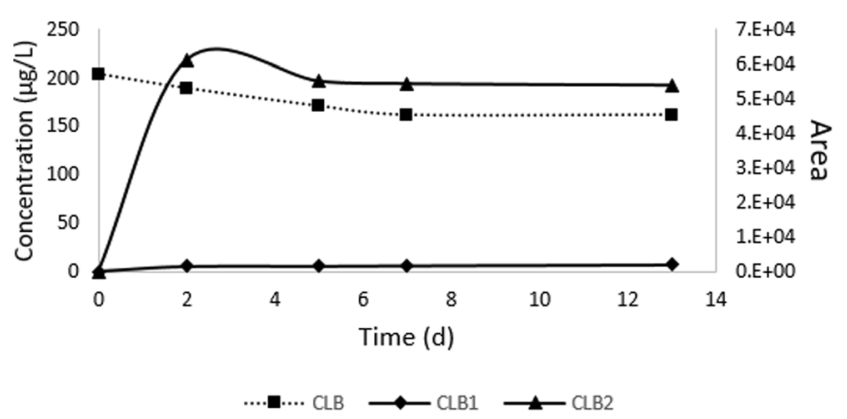

C

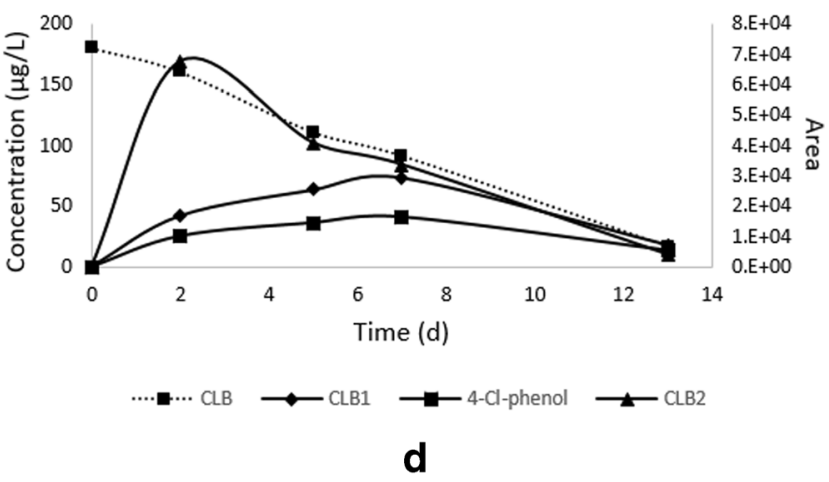

Fig. 2 Biodegradation and TPs formation kinetics of CLB by T. asperellum (a absence, b presence of 1-aminobenzotriazole (ABT)) and T. harzanium (c absence, $\mathbf{d}$ presence of 1 -aminobenzotriazole (ABT)) after 13 days of incubation; CLB2 is plotted in function of area

shown that CYP450 are not the sole intracellular enzymes, which might be responsible for the non-steroidal inflammatories (NSAIs) by Trametes hursita (Haroune et al. 2017). At this stage, compounds uptake and intracellular transformations by others enzymes than CYP450 could not be ruled out. This assumption was reasonable because it is known that a

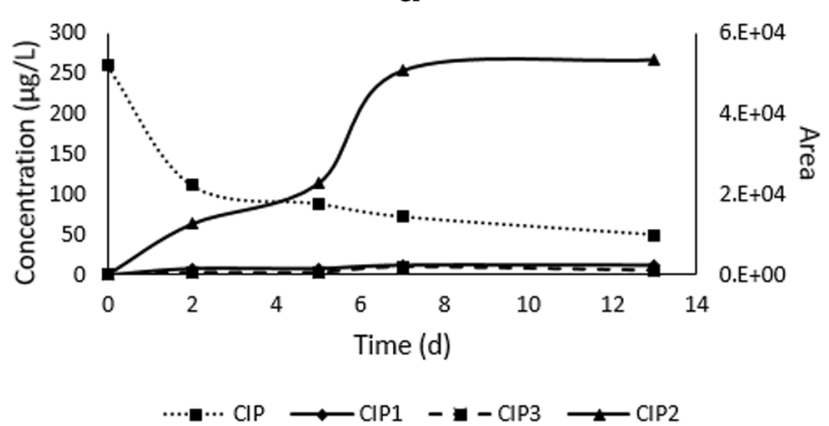

b

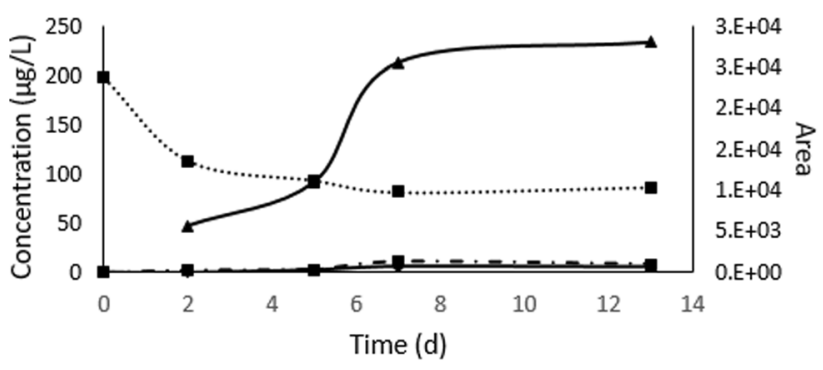

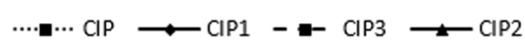

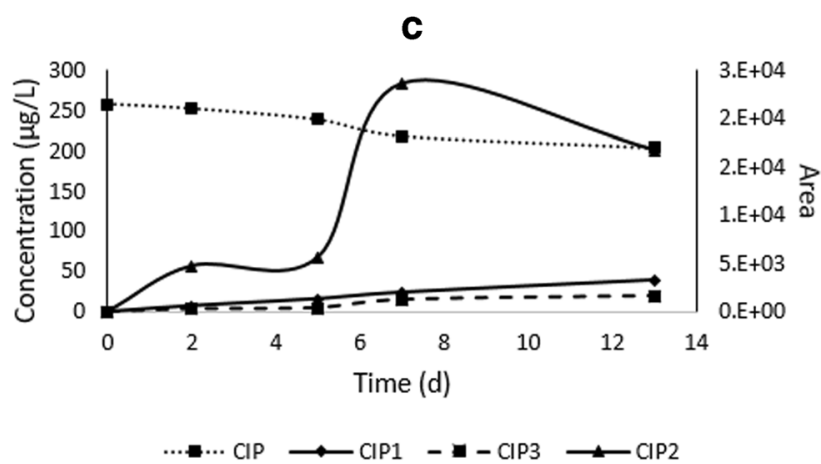

d

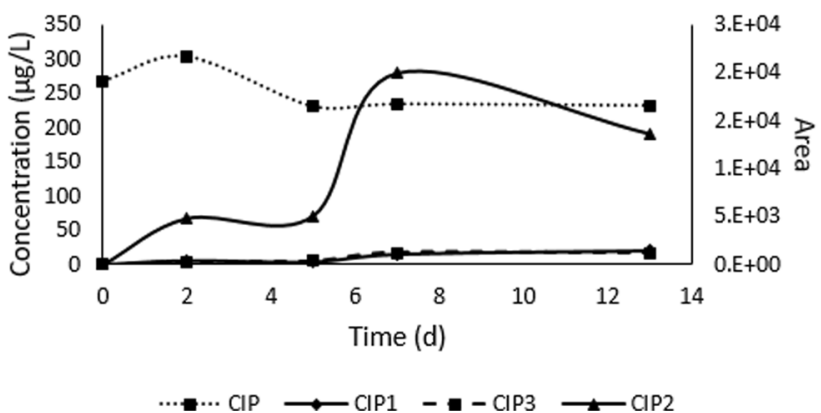

Fig. 3 Biodegradation and TPs formation kinetics of CIP by T. asperellum (a absence, b presence of 1-aminobenzotriazole (ABT)) and T. harzanium (c absence, $\mathbf{d}$ presence of 1-aminobenzotriazole (ABT)) after 13 days of incubation; CIP2 is plotted in function of area 
T. asperellum and T. harzanium strains are able to secrete CYP450 enzymes (Chadha et al. 2018). TPs appeared to accumulate against time except for TPs of CLB for which bell shape profiles were observed implying a further degradation of these TPs after 7 days of incubation (Fig. 2a and c). In contrast, after ABT addition, TPs of CLB accumulated against time with a potential contribution of CYP450 in their further transformations (Fig. 2b and d). Most of CIP and OFL TPs were only slightly affected by ABT addition. Exceptions were CIP1 and OFL1 whose formation only started after 5 days and 7 days of incubation, respectively (Fig. 3b, d; Fig. 1SM). This might reflect a slower fluoroquinolone uptake by fungi in presence of ABT as previously reported for the ketoprofen analgesic (Marco-Urrea et al. 2010).

On the whole, these results indicated that both intracellular and extracellular enzymes were participating in CECs biodegradation. According to the results, it is reasonable to say that the contribution of intracellular enzymes contributed in a lesser extent than extracellular enzymes. This is somewhat different to the results obtained with WRF where it was shown that the contribution of intracellular and extracellular enzymes was equally important.

\section{Identification of transformation products and transformation pathways}

To the authors' knowledge, this work is the first one to report on the biodegradation of CLB by fungi species (i.e., Trichoderma spp.), while fluoroquinolones biodegradation has been previously investigated by different species including WRF (Čvančarová et al. 2015; Maia et al. 2014; Parshikov et al. 2001; Prieto et al. 2011; Wetzstein et al. 1999). Two different strategies were followed to identify TPs: (a) a suspect exact mass screening of pseudo-molecular ions $\left([\mathrm{M}+\mathrm{H}]^{+}\right.$or $[\mathrm{M}-$ $\mathrm{H}]^{-}$of plausible TPs identified in previous degradation studies and (b)suggested masses obtained from theoretical transformation reactions using the BiotransformationMassDefects software, where full-scan MS data of treated samples $(t>0)$ are compared with a sample at $t=0 \mathrm{~h}$ and controls to identify compound masses formed during biodegradation experiments. The only masses considered as TP candidates where the ones whose intensity changed over the time course of the biodegradation experiments and which were not present in the control experiments.

Following these analytical procedures, three, three and four TPs were identified for CLB, CIP and OFL, respectively. Extracted Ion Chromatograms showing identified TPs are included in SM (Fig. 2SM, Fig. 3SM, Fig. 4SM, Fig. 5SM and Fig. 6SM). Accurate mass measurements, MS/MS data of each TP together with their LC retention time (RT) and proposed chemical formula are reported in Table 1. MS/MS spectra of newly identified TPs are also reported in SM (Fig. 7SM, Fig. 8SM, Fig. 9SM, Fig. 10SM, Fig. 11SM and Fig. 12SM).
CIP transformation products Identical TPs (CIP1, CIP2 and CIP3) were identified with both Trichoderma strains, but if a mass balance was nearly achieved with $T$. harzanium, this was not true with T. asperellum (see Fig. 3), underlying the inability to detect all TPs in this latter case. CIP1 exhibited a protonated molecular ion at $\mathrm{m} / \mathrm{z} 306.1252$ and a fragment ion corresponding to water losses ( $\mathrm{m} / \mathrm{z} 288.1146)$ (Table 1$)$. The structure of this TP was assigned to desethylene CIP and was confirmed by using an authentic standard. CIP1 was obtained by piperazinyl ring cleavage. CIP2 and CIP3 (m/z 374.1516 and $\mathrm{m} / \mathrm{z}$ 360.1359) were identified as N-acetyl CIP and formamide CIP, respectively; CIP2 was identified by the suspect mass screening approach, while CIP3 was confirmed by the use of a reference standard. Acetylation and formylation are common strategies of microorganisms to reduce fluoroquinolones toxicity and were previously reported under different biological treatment systems including biodegradation by WRF (Prieto et al. 2011). All these TPs were also detected with different others fungi (Čvančarová et al. 2015; Parshikov et al. 2001; Prieto et al. 2011; Wetzstein et al. 1999). The degradation of CIP from artificial contaminated soil was achieved thanks to the enzymatic activities of Penicillium notatum, Aspergillus fumigatus, Penicillium frequentans and Penicillium exspansum (Zhang et al. 2012), while Parshikov and co-workers showed the ability of Trichodermaviride to produce conjugated CIP metabolites through chemical processes (Parshikov et al. 2001).

OFL transformation products Identical TPs (OFL1, OFL2, OFL3 and OFL4) were tentatively identified using both Trichoderma strains. A mass balance could not be established due to the lack of analytical standards for quantification purposes. However, on the basis of peak area, OFL 2 was found to be the predominant TP. With a pseudo molecular ion at $\mathrm{m} / \mathrm{z}$ 348.1350 and a fragment ion corresponding to water losses, OFL1 was identified as N-desmethyl-OFL as previously reported (Gros et al. 2014). OFL1 was also detected under biodegradation by $T$. versicolor (Čvančarová et al. 2015) and by mixed bacterial medium (Maia et al. 2014). OFL2 was detected by suspect screening approach and was characterized by an increase of an oxygen atom mass unit ( $\mathrm{m} / \mathrm{z}$ 378.1461) with respect to OFL likely due to hydroxylation processes. Due to non-specific fragmentations $\left(\mathrm{H}_{2} \mathrm{O}\right.$ and $\mathrm{CO}_{2}$ losses), it was difficult to assign a definitive chemical structure to this TP with a high degree of certainty. In particular, it was not possible to discriminate between alkane hydroxylation and aromatic ring hydroxylation. The structure of OFL3 (m/z 318.1612) was tentatively assigned to decarboxylated OFL while with a loss of $2 \times \mathrm{H}$ mass units with respect to OFL, OFL4 (m/z 364.1573) was likely generated after the reduction of the carbonyl function into a secondary alcohol. Čvančarováand coauthors (Čvančarová et al. 2015) reported a metabolite with $\mathrm{m} / \mathrm{z}$ 364. However, its exact mass and its structural formula 
t1.1 Table 1 Summary of CIP, OFL and CLB identified TPs together with their parent compounds, retention time (RT), measured and theoretical [M $+\mathrm{H}]^{+}$ or $[\mathrm{M}-\mathrm{H}]^{-}$ions, MS/MS fragment ions and tentative structures

\begin{tabular}{|c|c|c|c|c|c|c|c|c|}
\hline $\mathrm{t} 1.2$ & Compound & Ion & RT (min) & Trichoderma sp. & Relative mass error (ppm) & Observed $\mathrm{m} / \mathrm{z}$ & Theoretical m/z & Formula \\
\hline $\begin{array}{l}\mathrm{t} 1.3 \\
\mathrm{t} 1.4\end{array}$ & CIP & {$[\mathrm{M}+\mathrm{H}]^{+}$} & $\begin{array}{l}2.6 \\
2.6\end{array}$ & $\begin{array}{l}T . \text { harzanium } \\
T \text {. asperellum }\end{array}$ & $\begin{array}{l}-1.50 \\
-2.10\end{array}$ & $\begin{array}{l}332.1405 \\
332.1403\end{array}$ & 332.1410 & $\mathrm{C}_{17} \mathrm{H}_{18} \mathrm{FN}_{3} \mathrm{O}_{3}$ \\
\hline $\mathrm{t} 1.5$ & CIP1 & $\begin{array}{l}{[\mathrm{M}+\mathrm{H}]^{+}} \\
{\left[\mathrm{M}+\mathrm{H}-\mathrm{H}_{2} \mathrm{O}\right]^{+}} \\
{\left[\mathrm{M}+\mathrm{H}-\mathrm{H}_{2} \mathrm{O}-20\right]^{+}}\end{array}$ & 2.4 & $T$. asperellum & $\begin{array}{l}-0.32 \\
1.04 \\
-16.78 \\
0.65 \\
-3.12 \\
5.96\end{array}$ & $\begin{array}{l}306.1252 \\
288.1146 \\
268.1036 \\
306.1255 \\
288.1134 \\
268.1097\end{array}$ & $\begin{array}{l}306.1253 \\
288.1143 \\
268.1081\end{array}$ & $\mathrm{C}_{15} \mathrm{H}_{16} \mathrm{FN}_{3} \mathrm{O}_{3}$ \\
\hline $\begin{array}{l}\mathrm{t} 1.7 \\
\mathrm{t} 1.8\end{array}$ & CIP2 & $\begin{array}{l}{[\mathrm{M}+\mathrm{H}]^{+}} \\
{\left[\mathrm{M}+\mathrm{H}-\mathrm{H}_{2} \mathrm{O}\right]^{+}}\end{array}$ & $\begin{array}{l}3.8 \\
3.8\end{array}$ & $\begin{array}{l}T . \text { harzanium } \\
T \text {. asperellum }\end{array}$ & $\begin{array}{l}0.26 \\
-0.28 \\
0.26 \\
-0.56\end{array}$ & $\begin{array}{l}374.1516 \\
356.1404 \\
374.1516 \\
356.1403\end{array}$ & $\begin{array}{l}374.1515 \\
356.1405\end{array}$ & $\mathrm{C}_{19} \mathrm{H}_{2} \mathrm{OFN}_{3} \mathrm{O}_{4}$ \\
\hline $\begin{array}{l}\mathrm{t} 1.9 \\
\mathrm{t} 1.10\end{array}$ & CIP3 & $\begin{array}{l}{[\mathrm{M}+\mathrm{H}]^{+}} \\
{\left[\mathrm{M}+\mathrm{H}-\mathrm{H}_{2} \mathrm{O}\right]^{+}}\end{array}$ & 3.7 & $\begin{array}{l}\text { T. harzanium } \\
T \text {. asperellum }\end{array}$ & $\begin{array}{l}0.00 \\
2.63 \\
0.00 \\
-0.29\end{array}$ & $\begin{array}{l}360.1359 \\
342.1257 \\
360.1359 \\
342.1247\end{array}$ & $\begin{array}{l}360.1359 \\
342.1248\end{array}$ & $\mathrm{C}_{18} \mathrm{H}_{18} \mathrm{FN}_{3} \mathrm{O}_{4}$ \\
\hline $\begin{array}{l}\mathrm{t} 1.11 \\
\mathrm{t} 1.12\end{array}$ & OFL & {$[\mathrm{M}+\mathrm{H}]^{+}$} & $\begin{array}{l}2.5 \\
2.5\end{array}$ & $\begin{array}{l}T . \text { harzanium } \\
T . \text { asperellum }\end{array}$ & $\begin{array}{l}-1.38 \\
-1.93\end{array}$ & $\begin{array}{l}362.1510 \\
362.1508\end{array}$ & 362.1515 & $\mathrm{C}_{18} \mathrm{H}_{20} \mathrm{FN}_{3} \mathrm{O}_{4}$ \\
\hline $\begin{array}{l}\mathrm{t} 1.13 \\
\mathrm{t} 1.14\end{array}$ & OFL1 & $\begin{array}{l}{[\mathrm{M}+\mathrm{H}]^{+}} \\
{\left[\mathrm{M}+\mathrm{H}-\mathrm{H}_{2} \mathrm{O}\right]^{+}}\end{array}$ & $\begin{array}{l}2.5 \\
2.5\end{array}$ & $\begin{array}{l}T \text {. harzanium } \\
T \text {. asperellum }\end{array}$ & $\begin{array}{l}-2.59 \\
0.30 \\
0.29 \\
-4.54\end{array}$ & $\begin{array}{l}348.1350 \\
330.1249 \\
348.1360 \\
330.1233\end{array}$ & $\begin{array}{l}348.1359 \\
330.1248\end{array}$ & $\mathrm{C}_{17} \mathrm{H}_{18} \mathrm{FN}_{3} \mathrm{O}_{4}$ \\
\hline $\mathrm{t} 1.15$ & OFL2 & $\begin{array}{l}{[\mathrm{M}+\mathrm{H}]^{+}} \\
{\left[\mathrm{M}+\mathrm{H}-\mathrm{H}_{2} \mathrm{O}\right]^{+}} \\
{\left[\mathrm{M}+\mathrm{H}-\mathrm{CO}_{2}\right]^{+}}\end{array}$ & 2.7 & $\begin{array}{l}T \text {. harzanium } \\
T \text {. asperellum }\end{array}$ & $\begin{array}{l}-1.06 \\
0.28 \\
0.30 \\
-0.53 \\
-0.83 \\
-0.60\end{array}$ & $\begin{array}{l}378.1461 \\
360.1355 \\
334.1562 \\
378.1463 \\
360.1351 \\
334.1559\end{array}$ & $\begin{array}{l}378.1465 \\
360.1354 \\
334.1561\end{array}$ & $\mathrm{C}_{18} \mathrm{H}_{20} \mathrm{FN}_{3} \mathrm{O}_{5}$ \\
\hline $\begin{array}{l}\mathrm{t} 1.17 \\
\mathrm{t} 1.18\end{array}$ & OFL3 & $\begin{array}{l}{[\mathrm{M}+\mathrm{H}]^{+}} \\
{[\mathrm{M}+\mathrm{H}-57]^{+}}\end{array}$ & $\begin{array}{l}2.5 \\
2.5\end{array}$ & $\begin{array}{l}\text { T. harzanium } \\
T \text {. asperellum }\end{array}$ & $\begin{array}{l}-1.57 \\
0.00 \\
0.00 \\
8.43\end{array}$ & $\begin{array}{l}318.1612 \\
261.1034 \\
318.1617 \\
261.1056\end{array}$ & $\begin{array}{l}318.1617 \\
261.1034\end{array}$ & $\mathrm{C}_{17} \mathrm{H}_{20} \mathrm{FN}_{3} \mathrm{O}_{5}$ \\
\hline $\begin{array}{l}\mathrm{t} 1.19 \\
\mathrm{t} 1.20\end{array}$ & OFL4 & $\begin{array}{l}{[\mathrm{M}+\mathrm{H}]^{+}} \\
{[\mathrm{M}+\mathrm{H}-46]^{+}}\end{array}$ & $\begin{array}{l}2.5 \\
2.5\end{array}$ & $\begin{array}{l}\text { T. harzanium } \\
\text { T. asperellum }\end{array}$ & $\begin{array}{l}3.1 \\
-2.51 \\
2.5 \\
5.03\end{array}$ & $\begin{array}{l}364.1573 \\
318.1604 \\
364.1562 \\
318.1628\end{array}$ & $\begin{array}{l}364.1672 \\
318.1612\end{array}$ & $\mathrm{C}_{18} \mathrm{H}_{22} \mathrm{FN}_{3} \mathrm{O}_{4}$ \\
\hline $\begin{array}{l}\mathrm{t} 1.21 \\
\mathrm{t} 1.22\end{array}$ & CLB & {$[\mathrm{M}+\mathrm{H}]^{+}$} & $\begin{array}{l}4.9 \\
4.9\end{array}$ & $\begin{array}{l}T . \text { harzanium } \\
T . \text { asperellum }\end{array}$ & $\begin{array}{l}3.07 \\
7.85\end{array}$ & $\begin{array}{l}293.1065 \\
293.1079\end{array}$ & 293.1056 & $\mathrm{C}_{15} \mathrm{H}_{17} \mathrm{ClN}_{2} \mathrm{O}_{2}$ \\
\hline $\begin{array}{l}\mathrm{t} 1.23 \\
\mathrm{t} 1.24\end{array}$ & CLB1 & $\begin{array}{l}{[\mathrm{M}+\mathrm{H}]^{+}} \\
{[\mathrm{M}+\mathrm{H}-226]^{+}}\end{array}$ & $\begin{array}{l}4.3 \\
4.3\end{array}$ & $\begin{array}{l}\text { T. harzanium } \\
T \text {. asperellum }\end{array}$ & $\begin{array}{l}-4.07 \\
0.00 \\
16.26 \\
1.45\end{array}$ & $\begin{array}{l}295.1201 \\
69.0443 \\
295.1261 \\
69.0448\end{array}$ & $\begin{array}{l}295.1213 \\
69.0447\end{array}$ & $\mathrm{C}_{15} \mathrm{H}_{19} \mathrm{ClN}_{2} \mathrm{O}_{2}$ \\
\hline $\begin{array}{l}\mathrm{t} 1.25 \\
\mathrm{t} 1.26\end{array}$ & CLB2 & $\begin{array}{l}{[\mathrm{M}+\mathrm{H}]^{+}} \\
{[\mathrm{M}+\mathrm{H}-242]^{+}}\end{array}$ & 3.9 & $T$. harzanium & $\begin{array}{l}1.93 \\
27.52 \\
8.04 \\
26.07\end{array}$ & $\begin{array}{l}311.1168 \\
69.0466 \\
311.1187 \\
69.0465\end{array}$ & $\begin{array}{l}311.1162 \\
69.0447\end{array}$ & $\mathrm{C}_{15} \mathrm{H}_{19} \mathrm{ClN}_{2} \mathrm{O}_{3}$ \\
\hline $\mathrm{t} 1.27$ & 4-chlorophenol & $\begin{array}{l}{[\mathrm{M}-\mathrm{H}]^{-}} \\
{[\mathrm{M}-\mathrm{H}-\mathrm{HCl}]^{-}}\end{array}$ & 5.3 & $T$. harzanium & $\begin{array}{l}3.15 \\
-5.49\end{array}$ & $\begin{array}{l}126.9955 \\
91.0184\end{array}$ & $\begin{array}{l}126.9951 \\
91.0189\end{array}$ & $\mathrm{C}_{6} \mathrm{H}_{5} \mathrm{ClO}$ \\
\hline
\end{tabular}

439 did not match to the one in our experiments. This led us to 440 propose another structure for this TP. Due to the small amount 441 of OFL2, OFL3 and OFL4 found in the sample extracts, the 442 obtained mass spectra information did not permit a definitive 443 structure elucidation of these TPs.
CLB transformation products CLB1 and CLB2 were detected with both Trichoderma strains, while an additional TP (i.e., 4chlorophenol) was also detected with the T. harzanium strain in the negative mode of ionization as shown in Fig. 4. CLB1 exhibited a protonated molecular ion at $\mathrm{m} / \mathrm{z} 295.1201$ 
corresponding to an increase of $2 \times \mathrm{H}$ mass unit with respect to CLB due to the reduction of the carbonyl group to a secondary alcohol to give CLB-OH. CLB1 was confirmed by the injection of an authentic standard and was detected under anaerobic activated sludge biodegradation conditions (Brienza and Chiron 2017) and under biodegradation by the freshwater algae Scenedesmus obliquus (Pan et al. 2018). CLB2 was characterized by a pseudo-molecular ion $[\mathrm{M}+\mathrm{H}]^{+}$at $\mathrm{m} / \mathrm{z}$ 311.1168 (Fig. 4), which corresponds to an increase of an oxygen mass unit probably related to the hydroxylation of CLB2. Due to the higher reactivity of the benzene ring in comparison with the tert-butyl alkyl group, hydroxylation is highly expected on the aromatic ring. 4-chlorophenol was likely obtained by ether cleavage of CLB and was detected for the first time.

On the basis of the identification of TPs by LC-HRMS, transformation pathways of CIP, OFL and CLB are proposed in Fig. 5. As observed, CIP and OFL did not share common transformation pathways. CIP transformation was mainly featured by oxidation of the pyperazinyl ring as well as by conjugation reactions leading to acetyl-N-CIP and formyl-NCIP. These transformations were previously reported with WRF and with filamentous fungi (Olicón-Hernández et al. 2017).

In contrast, OFL mainly underwent hydroxylation processes. This was due to the requirement of $\mathrm{N}$-desmethylation of the piperazine ring before this latter been oxidized. Others minor pathways involved OFL decarboxylation reaction together with the carbonyl function reduction into secondary alcohol.

As far as CLB was concerned, the main transformation pathway involved the reduction of the carbonyl moiety. This was also in compliance with the possible involvement of carbonyl reductases, which catalyze ketone reduction by direct hydride transfer from NAD $(\mathrm{P}) \mathrm{H}$ cofactor. This reduction reaction was followed by a hydroxylation pathway. More interestingly was the detection of 4-chlorophenol as a major TP resulting from O-dealkylation reactions. These O-dealkylation reactions were related to fungal peroxygenase (PorajKobielska et al. 2011) and was previously observed during the course of the biotransformation of clarithromycin by $\mathrm{T}$. asperellum leading to the formation of descladonisylclarithromycin (Buchicchio et al. 2016).

As a whole, biotransformation of selected CECs included hydroxylation, oxidation/reduction and $\mathrm{N}$ - and $\mathrm{O}$ dealkylation reactions, indicating that the oxidoreductase extracellular enzymes, such as laccase and peroxidase, were mainly responsible for CEC degradation processes. Laccase enzymes are known to perform soft oxidation reactions such as hydroxylation, methylation, demethylation and deacetylation (Barr and Aust 1994), while peroxidases are more potent enzymes able to perform harder oxidative reactions such as $\mathrm{N}$ - and $\mathrm{O}$-dealkylation reactions. Consequently, Trichoderma spp. likely possess a machinery of unspecific enzymes, which may be similar to that of WRF and which could make them suitable for CEC residue elimination in wastewater or soil. The internal mechanism of detoxification mediated by CYP450 family has been pointed out as a main contributor for transforming different xenobiotics by fungi particularly by fungi characterized by a low secretion of lignin-modifying enzymes (e.g., ascomycota). However, this contribution was not so obvious in this study probably accounting for a slower degradation kinetics in comparison with studies with WRF.

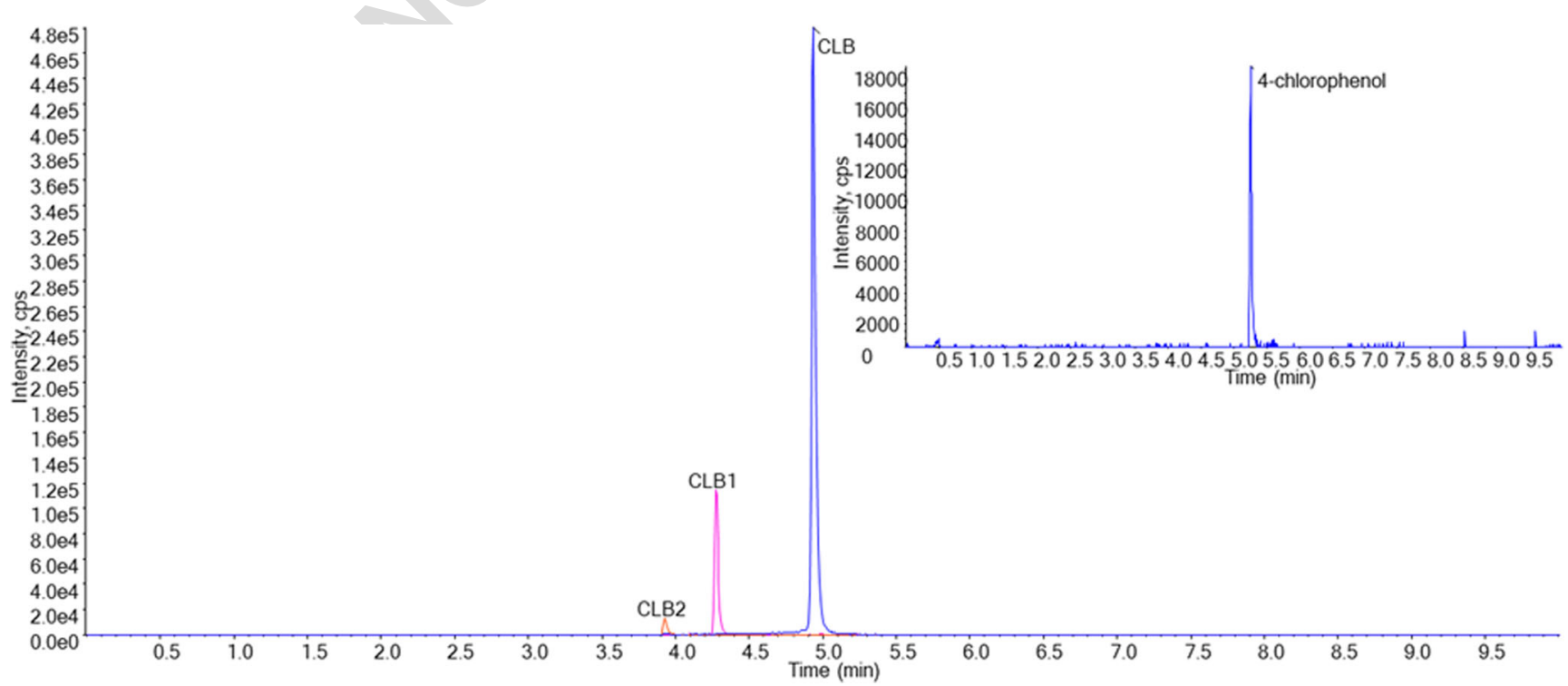

Fig. 4 Extracted Ion Chromatogram (XIC) corresponding to the analysis of TPs of climbazole after 7 days incubation in $T$. harzanium culture. Insert corresponds to analysis in negative ionization mode 

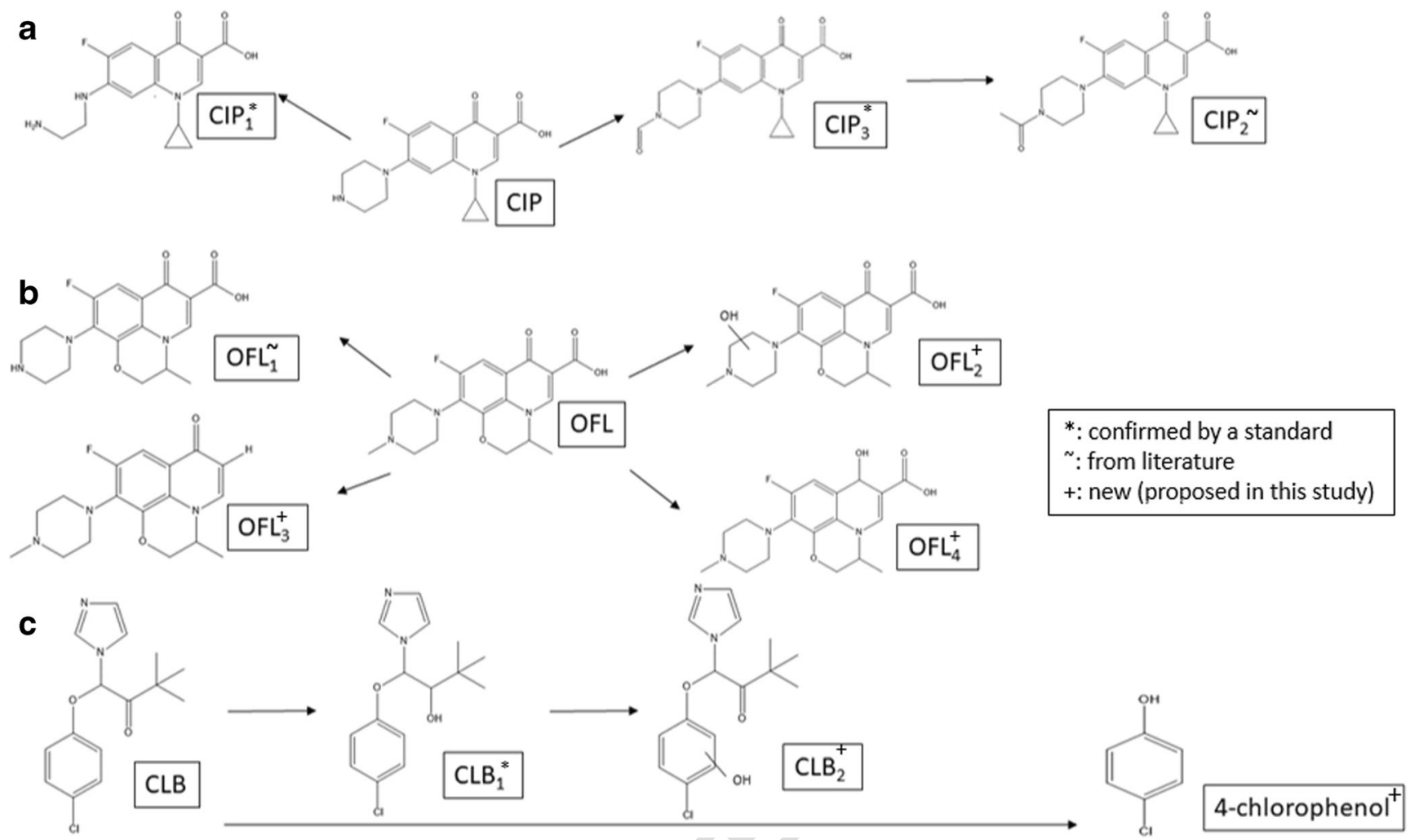

Fig. 5 Proposed transformation pathways of CIP (a), OFL (b) and CLB (c)

\section{Conclusion}

Filamentous fungi-mediated treatment of CECs is a promising and environmentally friendly technology. In this study, the fluoroquinolone antibiotics CIP and OFL and the CLB fungicide were efficiently removed by Trichoderma spp. in liquid medium. This study was one of the first ones reporting the capacity of these fungi to degrade CECs. The tentative identification of their transformation products was achieved, and biotransformation has turned out to be the predominant degradation process. The evidence of their degradability by Trichoderma spp. is of interest since CECs are poorly eliminated in conventional activated sludge treatments. Thanks to the high selectivity and mass accuracy provided by LCHRMS, a significant number of unknown TPs were tentatively identified in experiments at Erlenmeyer scale. The toxicity tests of the generated TPs were not taken into consideration in this work because of the low experimental concentrations applied. Transformation mechanisms relied on a wide array of enzymatic reactions including conjugation, hydroxylation and oxidation/reduction reactions likely due to an unspecific extracellular enzyme system. This result is promising because the degradation of a wide range of pharmaceuticals can be contemplated. Even though Trichoderma spp. have been found to grow rapidly in adverse environmental conditions, more research is needed to evaluate the effectiveness of these fungi to remove pharmaceutical residues at environmental concentrations in more realistic conditions such as in domestic wastewater effluents. Further experiments are also needed to optimize the capacity of Trichoderma spp. in degrading CECs and to assess the toxicity of the generated TPs.

Acknowledgments The authors thank the Water Challenges for a Changing World Joint Programming Initiative and Spanish Ministry of Economy, Industry and Competitiveness (MINECO). The authors also acknowledge SCIEX for providing the loan instrument LC/HRMS QTOF X500R.

Funding information This study has been financially supported by the EU through the WaterJPI-2015 AWARE project (PCIN-2017-067) and the Spanish national project (RTI2018-097158-B-C33). M. Brienza has a post-doc grant from MUSE - Montpellier Université d'Excellence.

\section{References}

Asgher M, Bhatti HN, Ashraf M, Legge RL (2008) Recent developments in biodegradation of industrial pollutants by white rot fungi and their enzyme system. Biodegradation 19:771-783. https://doi.org/10. 1007/s10532-008-9185-3

Badia-Fabregat M, Lucas D, Tuomivirta T, Fritze H, Pennanen T, Rodríguez-Mozaz S, Barceló D, Caminal G, Vicent T (2017) Study of the effect of the bacterial and fungal communities present in real wastewater effluents on the performance of fungal treatments. 
Sci Total Environ 579:366-377. https://doi.org/10.1016/j.scitotenv. 2016.11.088

Barr DP, Aust SD (1994) Mechanisms white rot fungi use to degrade pollutants. Environ Sci Technol 28. https://doi.org/10.1021/ es00051a724

Brienza M, Chiron S (2017) Enantioselective reductive transformation of climbazole: a concept towards quantitative biodegradation assessment in anaerobic biological treatment processes. Water Res 116: 203-210. https://doi.org/10.1016/j.watres.2017.03.037

Brienza M, Manasfi R, Chiron S (2019) Relevance of N-nitrosation reactions for secondary amines in nitrate-rich wastewater under UV-C treatment. Water Res 162:22-29. https://doi.org/10.1016/j.watres. 2019.06.055

Buchicchio A, Bianco G, Sofo A, Masi S, Caniani D (2016) Biodegradation of carbamazepine and clarithromycin by Trichoderma harzianum and Pleurotus ostreatus investigated by liquid chromatography - high-resolution tandem mass spectrometry (FTICR MS-IRMPD). Sci Total Environ 557-558:733-739. https://doi.org/10.1016/j.scitotenv.2016.03.119

Chadha S, Mehetre ST, Bansal R, Kuo A, Aerts A, Grigoriev IV, Druzhinina IS, Mukherjee PK (2018) Genome-wide analysis of cytochrome P450s of Trichoderma spp.: annotation and evolutionary relationships. Fungal Biol Biotechnol 5:12. https://doi.org/10.1186/ s40694-018-0056-3

Chen Y, Wang C, Wang Z, Huang S (2004) Assessment of the contamination and genotoxicity of soil irrigated with wastewater. Plant Soil 261:189-196. https://doi.org/10.1023/B:PLSO.0000035565.65775. $3 \mathrm{c}$

Couto CF, Lange LC, Amaral MCS (2019) Occurrence, fate and removal of pharmaceutically active compounds (PhACs) in water and wastewater treatment plants - a review. J Water Process Eng 32:100927. https://doi.org/10.1016/j.jwpe.2019.100927

Čvančarová M, Moeder M, Filipová A, Cajthaml T (2015) Biotransformation of fluoroquinolone antibiotics by ligninolytic fungi - metabolites, enzymes and residual antibacterial activity. Chemosphere 136:311-320. https://doi.org/10.1016/j. chemosphere.2014.12.012

Durán N, Esposito E (2000) Potential applications of oxidative enzymes and phenoloxidase-like compounds in wastewater and soil treatment: a review. Appl Catal B Environ 28:83-99. https://doi.org/10. 1016/S0926-3373(00)00168-5

Fatta-Kassinos D, Vasquez MI, Kümmerer K (2011) Transformation products of pharmaceuticals in surface waters and wastewater formed during photolysis and advanced oxidation processes - degradation, elucidation of byproducts and assessment of their biological potency. Chemosphere 85:693-709. https://doi.org/10.1016/j. chemosphere.2011.06.082

Gros M, Cruz-Morato C, Marco-Urrea E, Longrée P, Singer H, Sarrà M, Hollender J, Vicent T, Rodriguez-Mozaz S, Barceló D (2014) Biodegradation of the X-ray contrast agent iopromide and the fluoroquinolone antibiotic ofloxacin by the white rot fungus Trametes versicolor in hospital wastewaters and identification of degradation products. Water Res 60:228-241. https://doi.org/10.1016/j.watres. 2014.04.042

Haroune L, Saibi S, Cabana H, Bellenger J-P (2017) Intracellular enzymes contribution to the biocatalytic removal of pharmaceuticals by Trametes hirsuta. Environ Sci Technol 51:897-904. https://doi. org/10.1021/acs.est.6b04409

Hoseinzadeh S, Shahabivand S, Aliloo AA (2017) Toxic metals accumulation in Trichoderma asperellum and T. harzianum. Microbiology 86:728-736. https://doi.org/10.1134/S0026261717060066

Huang Y, Kong M, Westerman D, Xu EG, Coffin S, Cochran KH, Liu Y, Richardson SD, Schlenk D, Dionysiou DD (2018) Effects of HCO $3^{-}$on degradation of toxic contaminants of emerging concern by UV/NO ${ }_{3}^{-}$. Environ Sci Technol 52:12697-12707. https://doi.org/ 10.1021/acs.est.8b04383
Hultberg M, Bodin H (2017) Fungi-based treatment of brewery wastewater-biomass production and nutrient reduction. Appl Microbiol Biotechnol 101:4791-4798. https://doi.org/10.1007/ s00253-017-8185-9

Jelic A, Cruz-Morató C, Marco-Urrea E, Sarrà M, Perez S, Vicent T, Petrović M, Barcelo D (2012) Degradation of carbamazepine by Trametes versicolor in an air pulsed fluidized bed bioreactor and identification of intermediates. Water Res 46:955-964. https://doi. org/10.1016/j.watres.2011.11.063

Kim S, Aga DS (2007) Potential ecological and human health impacts of antibiotics and antibiotic-resistant Bacteria from wastewater treatment plants. J Toxicol Environ Health B Crit Rev 10:559-573. https://doi.org/10.1080/15287390600975137

Kumar M, Jaiswal S, Sodhi KK, Shree P, Singh DK, Agrawal PK, Shukla P (2019) Antibiotics bioremediation: perspectives on its ecotoxicity and resistance. Environ Int 124:448-461. https://doi.org/10.1016/j. envint.2018.12.065

Kümmerer K (2011) Emerging contaminants versus micro-pollutants. Clean Soil Air Water 39:889-890. https://doi.org/10.1002/clen. 201110002

Libardi N, Soccol CR, Góes-Neto A, de Oliveira J, Vandenberghe LP d S (2017) Domestic wastewater as substrate for cellulase production by Trichoderma harzianum. Process Biochem 57:190-199. https://doi. org/10.1016/j.procbio.2017.03.006

Maia AS, Ribeiro AR, Amorim CL, Barreiro JC, Cass QB, Castro PML, Tiritan ME (2014) Degradation of fluoroquinolone antibiotics and identification of metabolites/transformation products by liquid chromatography-tandem mass spectrometry. J Chromatogr A 1333:87-98. https://doi.org/10.1016/j.chroma.2014.01.069

Marco-Urrea E, Pérez-Trujillo M, Cruz-Morató C, Caminal G, Vicent T (2010) White-rot fungus-mediated degradation of the analgesic ketoprofen and identification of intermediates by HPLC-DAD MS and NMR. Chemosphere 78:474-481. https://doi.org/10.1016/ j.chemosphere.2009.10.009

Olicón-Hernández DR, González-López J, Aranda E (2017) Overview on the biochemical potential of filamentous fungi to degrade pharmaceutical compounds. Front Microbiol 8:1792. https://doi.org/10. 3389/fmicb.2017.01792

Pan C-G, Peng F-J, Ying G-G (2018) Removal, biotransformation and toxicity variations of climbazole by freshwater algae Scenedesmus obliquus. Environ Pollut 240:534-540. https://doi.org/10.1016/j. envpol.2018.05.020

Parshikov IA, Heinze TM, Moody JD, Freeman JP, Williams AJ, Sutherland JB (2001) The fungus Pestalotiopsis guepini as a model for biotransformation of ciprofloxacin and norfloxacin. Appl Microbiol Biotechnol 56:474-477. https://doi.org/10.1007/ s002530100672

Petrie B, Barden R, Kasprzyk-Hordern B (2015) A review on emerging contaminants in wastewaters and the environment: current knowledge, understudied areas and recommendations for future monitoring. Water Res 72:3-27. https://doi.org/10.1016/j.watres.2014.08. 053

Phonsiri V, Choi S, Nguyen C, Tsai Y-L, Coss R, Kurwadkar S (2019) Monitoring occurrence and removal of selected pharmaceuticals in two different wastewater treatment plants. SN Appl Sci 1:798-711. https://doi.org/10.1007/s42452-019-0774-Z

Poraj-Kobielska M, Kinne M, Ullrich R, Scheibner K, Kayser G, Hammel KE, Hofrichter M (2011) Preparation of human drug metabolites using fungal peroxygenases. Biochem Pharmacol 82:789796. https://doi.org/10.1016/j.bcp.2011.06.020

Prieto A, Möder M, Rodil R, Adrian L, Marco-Urrea E (2011) Degradation of the antibiotics norfloxacin and ciprofloxacin by a white-rot fungus and identification of degradation products. Bioresour Technol 102:10987-10995. https://doi.org/10.1016/j. biortech.2011.08.055 
Togola A, Budzinski H (2008) Multi-residue analysis of pharmaceutical compounds in aqueous samples. J Chromatogr A 1177:150-158. https://doi.org/10.1016/j.chroma.2007.10.105

Wetzstein H-G, Stadler M, Tichy H-V, Dalhoff A, Karl W (1999) Degradation of ciprofloxacin by basidiomycetes and identification of metabolites generated by the brown rot FungusGloeophyllum striatum. Appl Environ Microbiol 65:1556-1563. https://doi.org/ 10.1128/AEM.65.4.1556-1563.1999

Zhang C-L, Guo X-L, Li B-Y, Wang Y (2012) Biodegradation of ciprofloxacin in soil. J Mol Liq 173:184-186. https://doi.org/10.1016/j. molliq.2012.06.016

Publisher's note Springer Nature remains neutral with regard to jurisdictional claims in published maps and institutional affiliations. activity during wood degradation by the white-rot basidiomycete. J Biotechnol 14 